\title{
Roles of Slip and Twinning on Indentation Formations in Magnesium Alloy Single Crystals $^{* 1}$
}

\author{
Momoka Watanabe ${ }^{1, * 2}$, Hiromoto Kitahara ${ }^{2,3, * 3}$, Yohei Takamatsu ${ }^{1, * 4}$, Masayuki Tsushida ${ }^{4}$ and \\ Shinji $\mathrm{Ando}^{3}$ \\ ${ }^{1}$ Graduate School of Science and Technology, Kumamoto University, Kumamoto 860-8555, Japan \\ ${ }^{2}$ Institute of Pulsed Power Science, Kumamoto University, Kumamoto 860-8555, Japan \\ ${ }^{3}$ Magnesium Research Center, Kumamoto University, Kumamoto 860-8555, Japan \\ ${ }^{4}$ Faculty of Engineering, Kumamoto University, Kumamoto 860-8555, Japan
}

Indentation tests using a spherical indenter were applied to six hexagonal close-packed structure single crystals - pure $\mathrm{Mg}, \mathrm{Mg}-0.5$ at $\% \mathrm{Al}$, $\mathrm{Mg}-0.5$ at $\% \mathrm{Zn}, \mathrm{Mg}-0.5$ at $\% \mathrm{Y}, \mathrm{Mg}-0.9$ at $\% \mathrm{Y}$, and pure $\mathrm{Zn}$ single crystals - to investigate the roles both slips and twinning induce on the formation of indentation. When indented on (0001), all single crystals displayed circular morphology without slip lines or twins. Mg and Mg alloys' indentation sizes were found dependent on critical resolved shear stress (CRSS) for basal slip in (0001) indentations, while Zn (0001) indentation size depends on CRSS for both basal and second order pyramidal slips. Conversely, when indented on (10 $\overline{10})$ and (12 10$)$, all single crystals displayed indentations elongated to [0001] surrounded by basal slip lines. Also, $\{10 \overline{1} 2\}$ twins were observed in $\mathrm{Mg}-0.5$ at $\% \mathrm{Al}$ and $\mathrm{Mg}-$ 0.5 at\% Zn but were scarce in Mg-Y. Pure Zn displayed second order pyramidal slips. Sizes of both (1010) and (1210) indentations were found dependent on CRSS for basal slips and for $\{10 \overline{1} 2\}$ twins. [doi:10.2320/matertrans.MT-M2019371]

(Received December 16, 2019; Accepted February 17, 2020; Published March 30, 2020)

Keywords: basal slip, second order pyramidal slip, $\{10 \overline{1} 2\}$ twin, critical resolved shear stress

\section{Introduction}

Hexagonal close-packed structure (HCP) materials include those such as magnesium, titanium, and zinc - are widely used in industrial fields. However, as HCP metals are known to show greater crystal orientation dependence on deformation behavior compared to cubic metals, deformation mechanisms have been studied using HCP single crystals. Tensile tests, ${ }^{1,2)}$ compression tests, ${ }^{3)}$ pure shear tests, ${ }^{4)}$ and fatigue tests ${ }^{5,6}$ of HCP single crystals have been conducted to investigate such deformation mechanisms. These studies have discovered activated slip systems, twin systems, and critical resolved shear stress (CRSS). These studies deformed entire single crystals by a uniaxial load and found that stress or strain varies within an individual grain in polycrystalline materials under deformation because, except at surfaces, all grains with different crystal orientations are bound together. Therefore, this study included indentation tests applied to pure magnesium single crystals to clarify local deformation behavior. Kitahara et $a l .{ }^{7)}$ have reported that activities of both slip and twin systems and indentation morphologies depends on crystal orientation when a spherical indenter was indented on low index planes of pure magnesium single crystals. Furthermore, crystal plasticity finite element method (CPFEM) showed that basal slips and $\langle c+a\rangle$ slips were activated when indented on (0001); also, basal slips and $\{10 \overline{1} 2\}$ twins were activated when indented on (1100) and $(11 \overline{2} 0)$ to form indentations. Nayyeri et al. ${ }^{8)}$ applied a spherical indenter to a large grain of pure magnesium polycrystals parallel to the direction inclined by 9.3 degrees

\footnotetext{
${ }^{* 1}$ This Paper was Originally Published in Japanese in J. Japan Inst. Met Mater. 83 (2019) 458-464.

${ }^{* 2}$ Graduate Student, Kumamoto University

${ }^{* 3}$ Corresponding author, E-mail: kitahara@msre.kumamoto-u.ac.jp

${ }^{* 4}$ Graduate Student, Kumamoto University. Present address: Kobe Steel,

Ltd., Takasago 676-8670, Japan
}

from [0001] and found indentations formed by activation of basal slips and $\{10 \overline{1} 2\}$ twins. In addition, activation of basal slips beneath indentations was analyzed using CPFEM. Deformation behavior beneath indentations has been calculated by numerical simulation, but our study was the first to have been experimentally confirmed.

CRSSs for basal slip and second order pyramidal $\langle c+a\rangle$ slip (SPCS) have been reported to change when aluminum, ${ }^{9-11)}$ zinc $^{12,13)}$ and yttrium ${ }^{13,14)}$ are added to magnesium. Also, the loading direction to cause $\{10 \overline{1} 2\}$ twins, a typical deformation twin of HCP metals, is known to depend on $c / a$; the critical value is $\sqrt{3} .^{15,16)}$ In magnesium, $\{10 \overline{1} 2\}$ twins occur in $c$-axis tension since $c / a=1.623$ is less than $\sqrt{3}$. On the other hand, $\{10 \overline{1} 2\}$ twins occur in $c$-axis compression in zinc, whose $c / a=1.856$ is larger than $\sqrt{3}$. Therefore, assuming similar indentation tests were performed either on magnesium alloys with different CRSS or on zinc with different twinning directions, they should reveal different deformation behavior than pure magnesium, with deformation behavior immediately below indentations expected to be experimentally estimable from differences in deformation behavior. In this study, indentation tests were applied to pure magnesium, $\mathrm{Mg}-\mathrm{Al}, \mathrm{Mg}-\mathrm{Zn}$, and $\mathrm{Mg}-\mathrm{Y}$ alloy and pure zinc single crystals, and the deformation behavior beneath indentations were investigated to clarify roles of slip and twinning on indentation formations.

\section{Experimental Procedures}

Pure magnesium, $\mathrm{Mg}-0.5$ at $\% \mathrm{Al}, \mathrm{Mg}-0.5$ at\% $\mathrm{Zn}, \mathrm{Mg}-$ 0.5 at $\% \mathrm{Y}, \mathrm{Mg}-0.9$ at\% $\mathrm{Y}$, and pure zinc single crystals were prepared, hereafter referred to as $\mathrm{Mg}, 05 \mathrm{Al}, 05 \mathrm{Zn}, 05 \mathrm{Y}, 09 \mathrm{Y}$, and $\mathrm{Zn}$. Purities of both $\mathrm{Mg}$ and $\mathrm{Zn}$ ingots were $99.99 \%$. Magnesium alloy ingots were produced using a high frequency induction furnace. Both ingot and seed crystal were set in a graphite mold to allow single crystals to be 
produced by the modified Bridgeman method. Chemical compositions of each individual crystal were analyzed using a high frequency inductively coupled plasma emission spectrometer (Hitachi High-Tech Science Corp, PS3500DD II). Indentation planes were confirmed by the X-ray back reflection Laue method: (0001), $\{10 \overline{1} 0\}$, and $\{1 \overline{2} 10\}$, and were chemically polished using a polishing cloth which was a soaked in a $20 \mathrm{ml} \mathrm{C}_{2} \mathrm{H}_{5} \mathrm{OH}+7 \mathrm{ml} \mathrm{H}_{2} \mathrm{O}_{2}+5 \mathrm{ml}$ $\mathrm{HNO}_{3}$ solution for both $\mathrm{Mg}$ and $\mathrm{Mg}$ alloy single crystals and a $4 \mathrm{ml} \mathrm{C}_{2} \mathrm{H}_{5} \mathrm{OH}+1 \mathrm{ml} \mathrm{H}_{2} \mathrm{O}_{2}+1 \mathrm{ml} \mathrm{HNO}_{3}$ solution for $\mathrm{Zn}$. After chemical polishing, $\mathrm{Mg}$ alloy single crystals were annealed in eight thermal cycles to remove strains induced by cutting and polishing. During thermal cycle annealing, the specimens were annealed at $673 \mathrm{~K}$. The temperature was then increased up to $723 \mathrm{~K}$. The holding time at each temperature was $3.6 \mathrm{ks}$, and the heating and cooling rates were $6.9 \times$ $10^{-3} \mathrm{~K} / \mathrm{s}$. After annealing, specimen surfaces were again chemically polished using the above polishing solution to remove contaminations and oxide films on surfaces. Each specimen thickness was at least 8 times or more than the depth of indentations, according to JIS Z2243. ${ }^{17)}$ Indentation tests were carried out using a diamond spherical indenter with a diameter of $1.0 \mathrm{~mm}$ and a hardness tester (SHIMADZU, Micro hardness tester type $\mathrm{M}$ ) at room temperature. The indentation load ranged from 0.98 to $4.90 \mathrm{~N}$ with a holding time of $15 \mathrm{~s}$. Indentation tests were performed four or five times, and diameters of indentations were measured in two directions on each plane. Also, areas of $\{10 \overline{1} 2\}$ twins around indentations were measured using their portions derived from optical micrographs. Indentation behavior was observed with an optical microscope, and slip lines and twins around indentations were analyzed geometrically. In Zn, distributions of dislocations around indentations were observed by the etch pit method. ${ }^{18)}$

\section{Results}

Figures 1 and 2 show optical micrographs of indentations on (0001) and (1010) in $\mathrm{Mg}, 05 \mathrm{Al}, 05 \mathrm{Zn}, 05 \mathrm{Y}, 09 \mathrm{Y}$ and $\mathrm{Zn}$ single crystals when indented at $4.90 \mathrm{~N}$. On (0001), all indentations displayed circular morphology. Also, slip lines and twins were scarce around indentations. Conversely, when
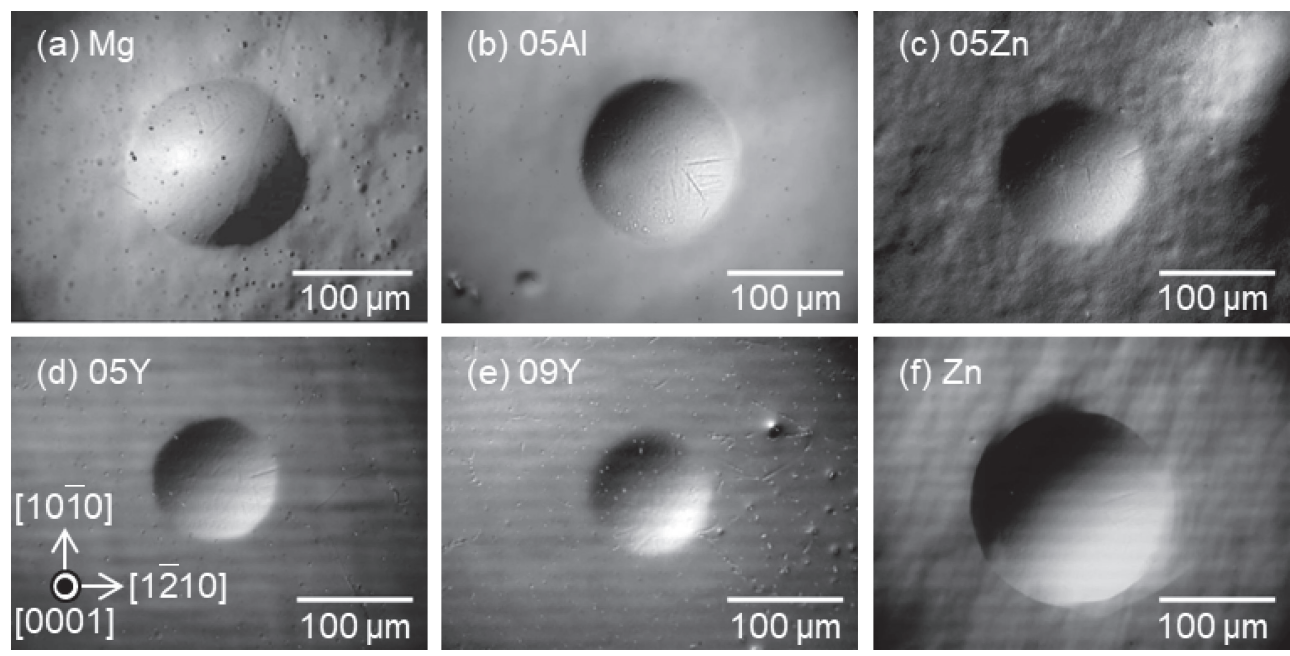

Fig. 1 Optical micrographs of indentations on (0001) in (a) Mg, (b) 05Al, (c) 05Zn, (d) 05Y, (e) 09Y and (f) Zn single crystals when indented at $4.90 \mathrm{~N}$.
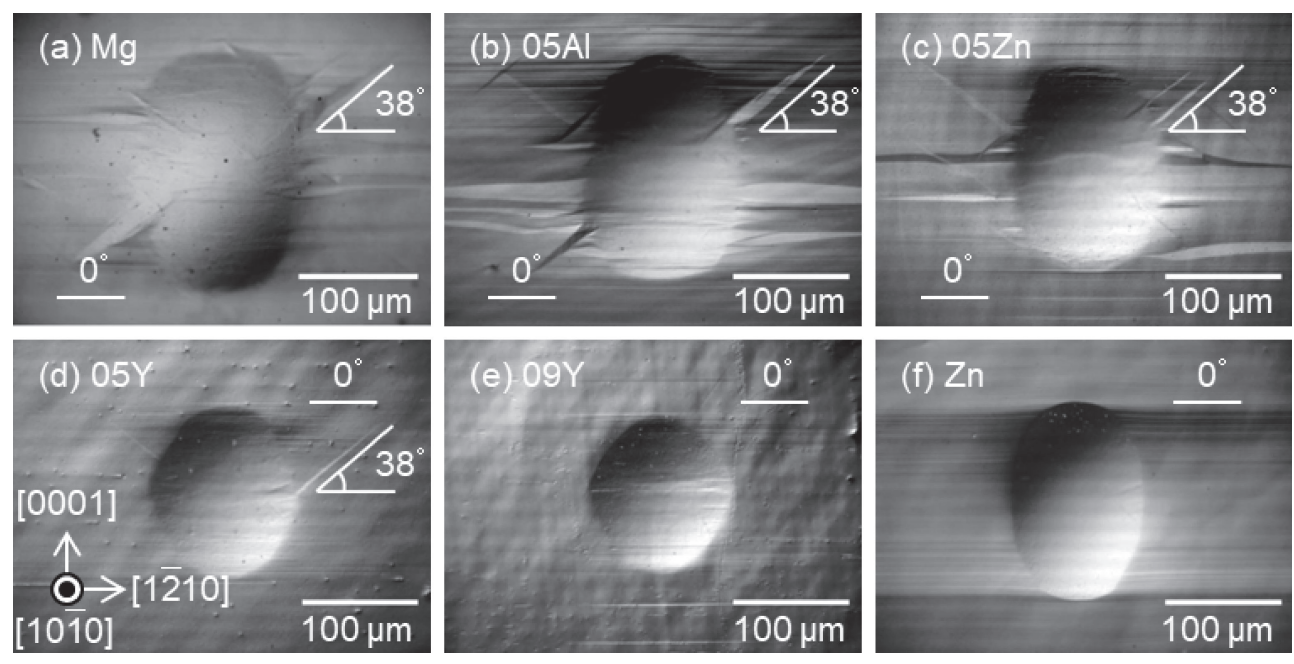

Fig. 2 Optical micrographs of indentations on (1010) in (a) Mg, (b) 05Al, (c) 05Zn, (d) 05Y, (e) 09Y and (f) Zn single crystals when indented at $4.90 \mathrm{~N}$. 

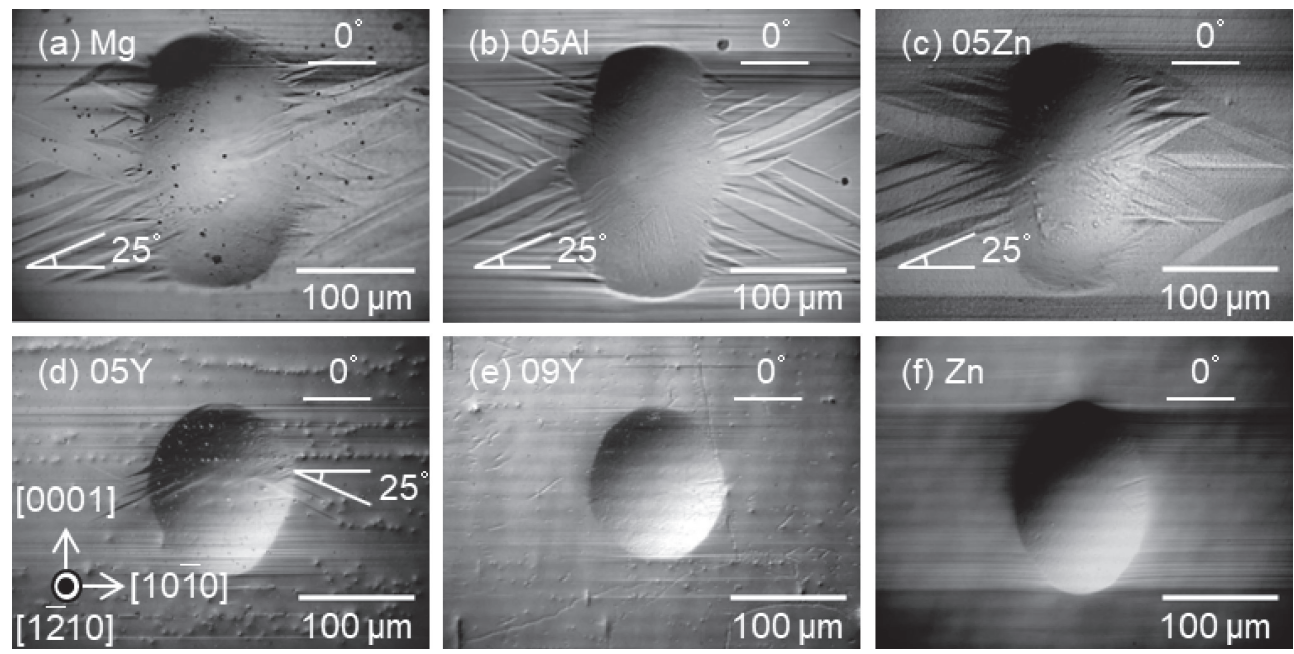

Fig. 3 Optical micrographs of indentations on (12̄10) in (a) $\mathrm{Mg}$, (b) 05Al, (c) 05Zn, (d) 05Y, (e) 09Y and (f) Zn single crystals when indented at $4.90 \mathrm{~N}$.

indented on (1010), $\mathrm{Mg}, 05 \mathrm{Al}$, and $05 \mathrm{Zn}$ displayed elliptical indentations elongated to [0001] with slip lines and twins mostly parallel to basal planes. $05 \mathrm{Y}$ and $09 \mathrm{Y}$, the two alloys with yttrium added, also showed indentations elongated to [0001], but the degree was smaller than that in $05 \mathrm{Al}$ and 05Zn. When $05 \mathrm{Y}$ and $09 \mathrm{Y}$ were compared, 09Y indentation morphology was more circular. Mineta et al. ${ }^{19)}$ also applied spherical indentation tests to $\mathrm{Mg}-1.3$ at $\% \mathrm{Y}$ and $\mathrm{Mg}-2.3$ at $\% \mathrm{Y}$ alloy single crystals and reported that indentation morphology becomes circular with increasing yttrium content. A small amount of both slip lines and twins were observed around $05 \mathrm{Y}$ indentations, while a small amount of slip lines and no twins were observed around 09Y indentations. In $\mathrm{Zn}$, indentations elongated to [0001] and slip lines were observed, but not twins. Twins were almost parallel to [1ํ10] or inclined approximately $38^{\circ}$ from [1 $\left.2 \overline{1} 10\right]$ except $09 \mathrm{Y}$ and $\mathrm{Zn}$. These twins were geometrically analyzed and characterized to be $\{10 \overline{1} 2\}$ twins. Figure 3 shows optical micrographs of indentations on $(1 \overline{2} 10)$ in $\mathrm{Mg}, 05 \mathrm{Al}, 05 \mathrm{Zn}$, 05Y, 09Y and $\mathrm{Zn}$. The indentation morphology, observed slip lines and twins were similar to those observed in (1010) indentations. Results of (1010) and (12 10$)$ are approximately the same and clear orientation dependence was not observed.

Figure 4 shows optical micrographs of etch pits on (1210) in $\mathrm{Zn}$ single crystals when indented at $4.90 \mathrm{~N}$. A large number of pits were observed around the indentation and were arrayed particularly on the upper, lower, left and right sides of the indentation. Pit arrays parallel to the basal plane and those inclined $58^{\circ}$ from [1010] were observed. Many pit arrays parallel to basal planes around indentation would be due to basal slip which easily activates in pure zinc. Also, pit arrays inclined $58^{\circ}$ from [10 $\left.\overline{1} 0\right]$ were geometrically analyzed and were found to be caused by SPCS. However, the amount was quite limited, and SPCS would rarely contribute to indentation formations. Also, when indented on (1010), pit arrays caused by basal slip and SPCS were observed, but pit arrays caused by SPCS were quite limited.

Figures 5, 6 and 7 show relationships between indentation sizes and indentation loads of $\mathrm{Mg}, 05 \mathrm{Al}, 05 \mathrm{Zn}, 05 \mathrm{Y}, 09 \mathrm{Y}$ and $\mathrm{Zn}$ on (0001), (1010) and (1210), respectively. In (0001)

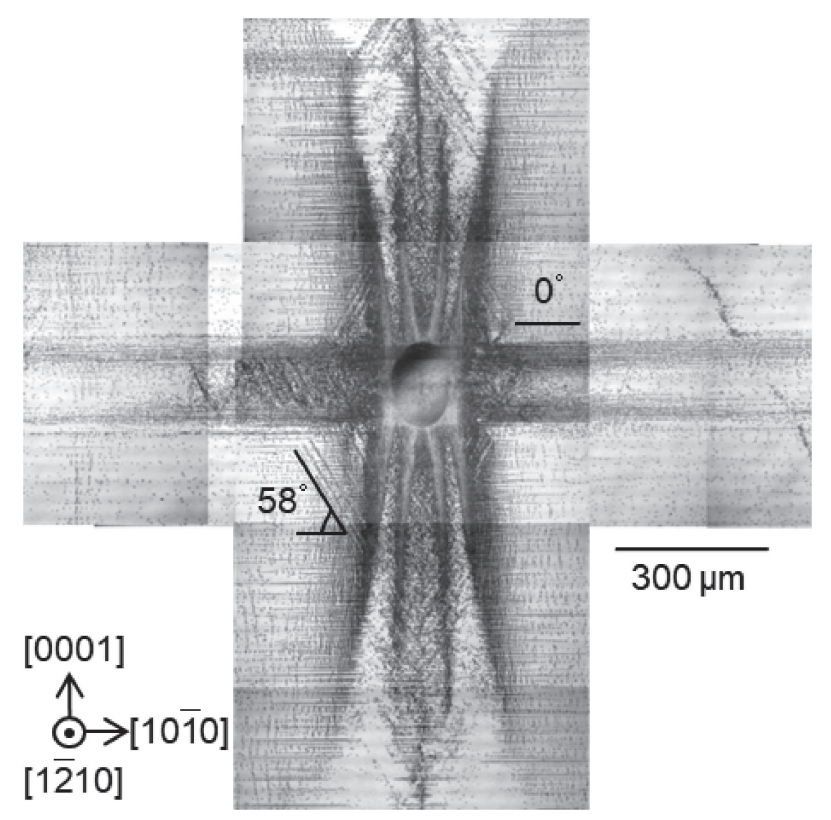

Fig. 4 Optical micrographs of etch pits on (1 $\overline{2} 10)$ in $\mathrm{Zn}$ single crystals when indented at $4.90 \mathrm{~N}$

indentations, indentation sizes were measured in [10 $\overline{1} 0]$ and [1ํ10] directions, while major and minor axes of elliptical indentations were measured when indented on (1010) and (12 10$)$. Here, the data in Fig. 5 are slightly shifted and plotted to prevent mutual overlap. As shown in Fig. 5, (0001) indentation sizes decreased by addition of alloying elements in magnesium. Indentation sizes minimalize in the following order: $\mathrm{Mg}, 05 \mathrm{Al}, 05 \mathrm{Zn}, 05 \mathrm{Y}$, and 09Y. Furthermore, indentation sizes of $\mathrm{Mg}$ and $\mathrm{Zn}$ were approximately identical. All (0001) indentation sizes in [10 $\overline{1} 0]$ and [1 $\overline{2} 10]$ directions were approximately identical, indicating that orientation dependence of indentation sizes was quite small. Figures 6 and 7 show that indentation sizes in [0001] direction were longer than those in $[1 \overline{2} 10]$ and $[10 \overline{1} 0]$ directions when indented on (1010) and (12 10$)$. Major/minor diameter ratios were measured when indented on $(10 \overline{1} 0)$ at $4.90 \mathrm{~N}$ and 
$\mathrm{O}[1010] \square[1210]$
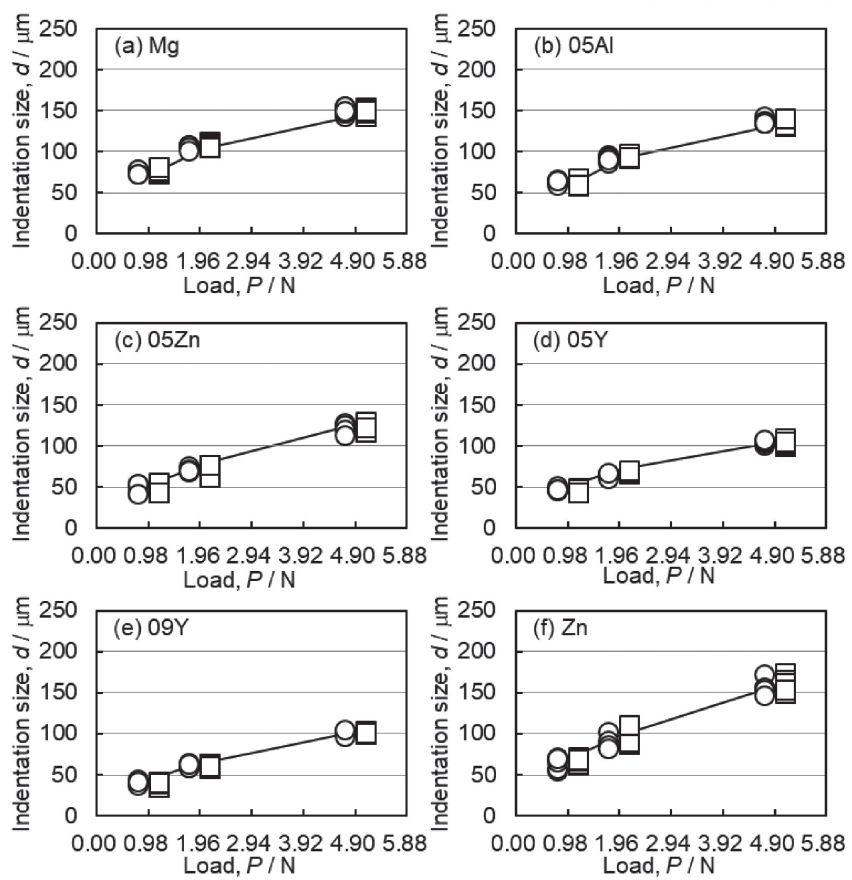

Fig. 5 Relationship between indentation size and indentation load of (a) $\mathrm{Mg}$, (b) 05Al, (c) 05Zn, (d) 05Y, (e) 09Y and (f) Zn on (0001).

$\bigcirc[0001] \square[1 \overline{2} 10]$
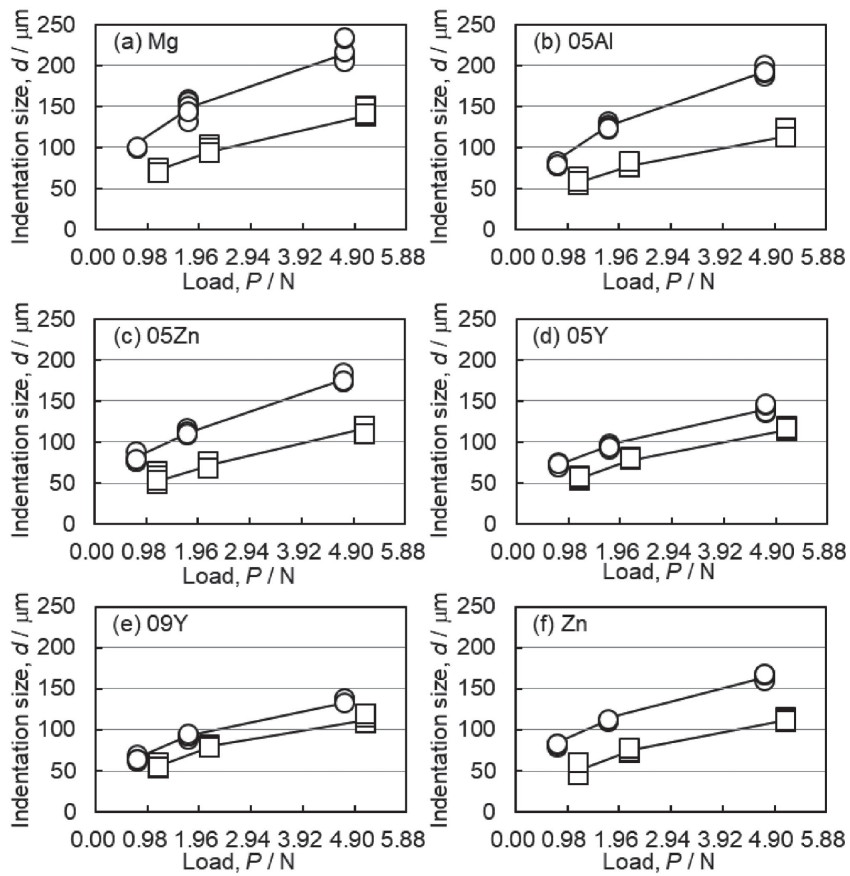

Fig. 6 Relationship between indentation size and indentation load of (a) $\mathrm{Mg}$, (b) 05Al, (c) 05Zn, (d) 05Y, (e) 09Y and (f) Zn on (1010)

displayed very minor differences: 1.54 in $\mathrm{Mg}, 1.63$ in $05 \mathrm{Al}$, and 1.52 in $05 \mathrm{Zn}$. In contrast, the ratios in $05 \mathrm{Y}$ and $09 \mathrm{Y}$ were, respectively, 1.20 and 1.19 , less than those in $\mathrm{Mg}$. Ratios closer to 1 result in more circular morphology. That anisotropy in $05 \mathrm{Y}$ and $09 \mathrm{Y}$ is less than that in $05 \mathrm{Al}$ and $05 \mathrm{Zn}$ was thus found. The same tendency was observed when indented on $(1 \overline{2} 10)$ at 4.90 N. Figure 6(f) and Fig. 7(f) show that indentation sizes in $\mathrm{Zn}$ were smaller than that in $\mathrm{Mg}$.
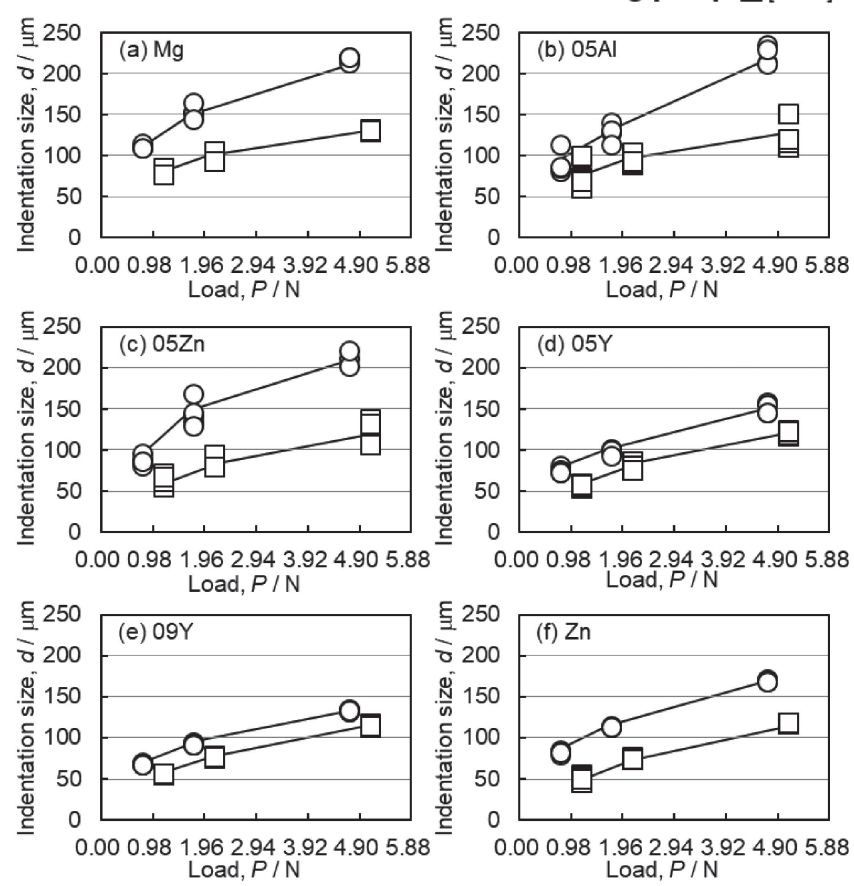

Fig. 7 Relationship between indentation size and indentation load of (a) $\mathrm{Mg}$, (b) 05Al, (c) 05Zn, (d) 05Y, (e) 09Y and (f) Zn on (12̄10).

\section{Discussion}

\subsection{Relationships between (0001) indentation sizes and slip activities}

Neither slip lines nor twins were observed around any (0001) indentations, indicating the indentations would be formed by slip deformation beneath indentations. Thus, indentation sizes and CRSSs for basal slip and SPCS were compared to investigate slip systems for formation of indentations when indented at $4.90 \mathrm{~N}$. Figure 8 shows (a) indentation sizes on (0001), (b) CRSS for basal slip and (c) CRSS for SPCS of $\mathrm{Mg}, \mathrm{Mg}$ alloy and $\mathrm{Zn}$ single crystals. When $\mathrm{Mg}$ and $\mathrm{Mg}$ alloy single crystals are compared, indentation sizes decrease and CRSSs for the basal slip increase in the following order: $05 \mathrm{Al}, 05 \mathrm{Zn}, 05 \mathrm{Y}$, and $09 \mathrm{Y}$. Conversely, no significant change in CRSS for SPCS was observed. Therefore, comparison of $\mathrm{Mg}$ and $\mathrm{Mg}$ alloy single crystals display indentation size correspondence between CRSS and basal slip. Comparison of $\mathrm{Mg}$ and $\mathrm{Zn}$ showed indentation sizes in $\mathrm{Zn}$ larger than those in $\mathrm{Mg}$ and that CRSS for SPCS in $\mathrm{Zn}$ is $1 / 10$ or less than that in $\mathrm{Mg}$. On the other hand, basal slip activities were very similar as CRSSs for basal slip in both $\mathrm{Mg}$ and $\mathrm{Zn}$ are almost identical. Therefore, the difference between indentation sizes in $\mathrm{Mg}$ and $\mathrm{Zn}$ can be explained by activation of SPCS. Figure 9 shows that schematic illustrations of deformation behavior beneath (0001) indentations in (a) $\mathrm{Mg}$ and $\mathrm{Mg}$ alloy, and (b) $\mathrm{Zn}$ single crystals. In (a) Mg and Mg alloy single crystals, shear stress is applied to basal planes as they are bent by indenters; further, basal slips are easily activated due to their low CRSS. In three-point bending deformation ${ }^{25}$ of pure magnesium single crystals, basal slips have been reported to be easily activated even when basal planes are parallel to the neutral plane. Conversely, in (b) Zn, not only basal slip but also 


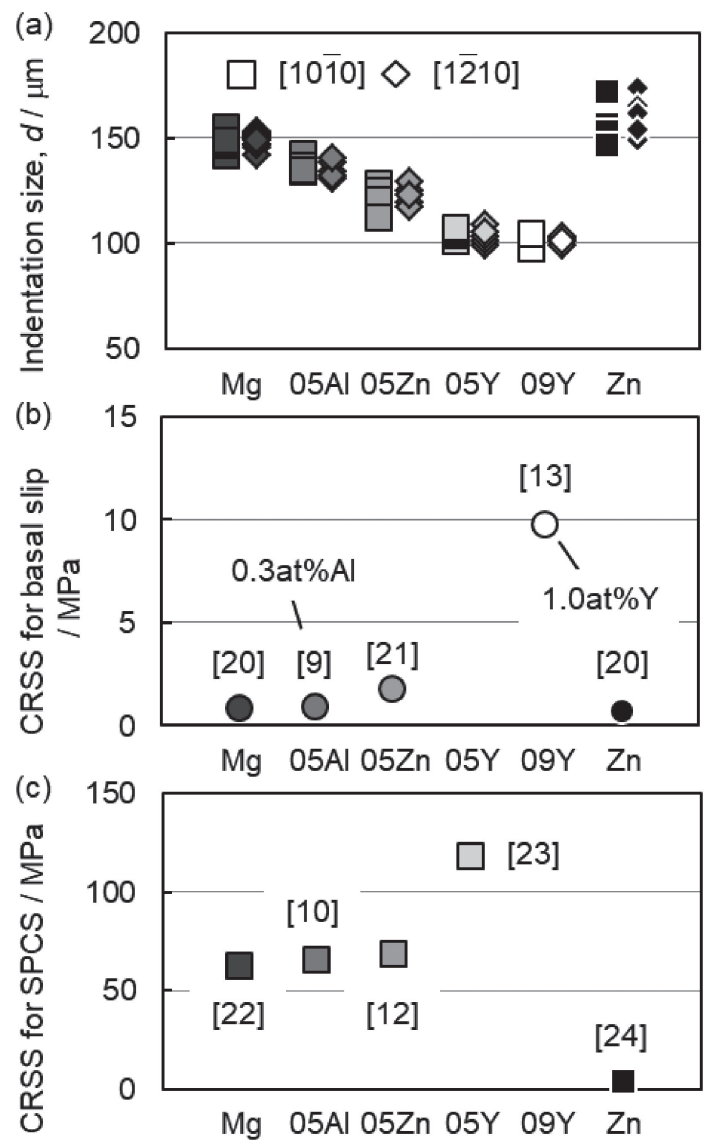

Fig. 8 (a) Indentation size on (0001), (b) CRSS for basal slip and (c) CRSS for SPCS in $\mathrm{Mg}, \mathrm{Mg}$ alloy and $\mathrm{Zn}$ single crystals.

(a)

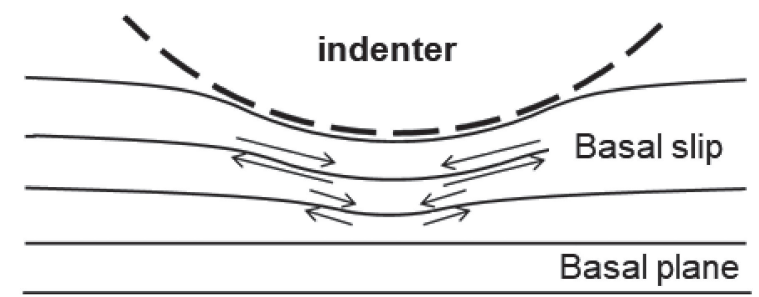

(b)

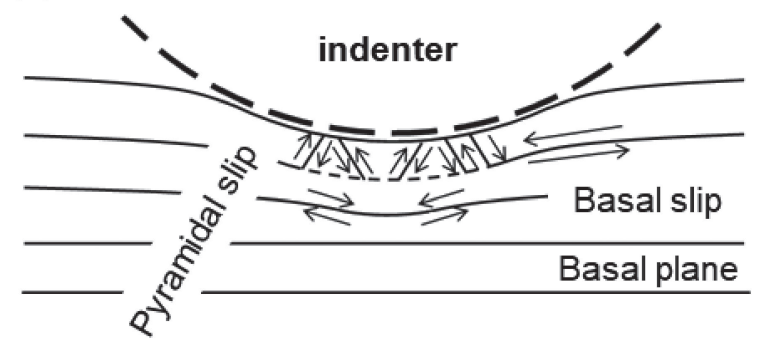

Fig. 9 Schematic illustrations of deformation behavior beneath (0001) indentations in (a) $\mathrm{Mg}$ and $\mathrm{Mg}$ alloy, and (b) $\mathrm{Zn}$ single crystals.

SPCS with lower CRSS is activated beneath indentations. Thus, indentation sizes in $\mathrm{Mg}$ and $\mathrm{Mg}$ alloy single crystals were found to greatly depend on CRSS for basal slip, the main slip, when indented on (0001). On the other hand, indentation sizes in $\mathrm{Zn}$ were found to depend on CRSSs for basal slip and SPCS when indented on (0001). That is, (0001) indentations are formed due to activation of basal slip in $\mathrm{Mg}$
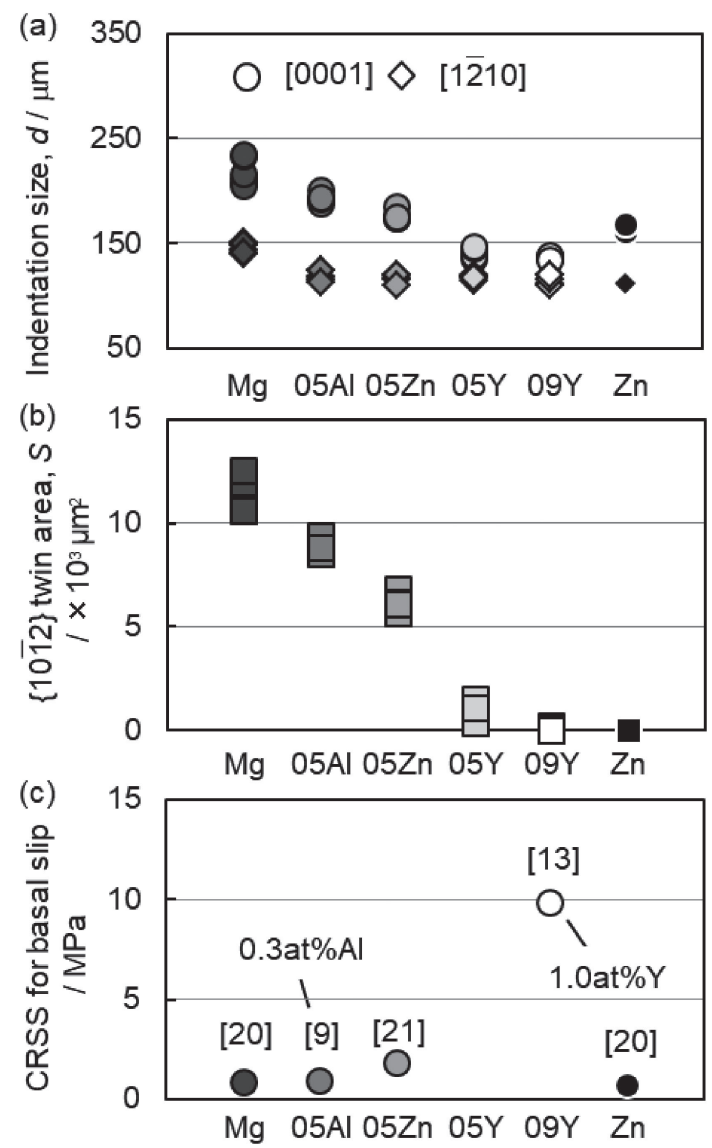

Fig. 10 (a) Indentation size on (10יㅣ), (b) $\{10 \overline{1} 2\}$ twin area and (c) CRSS for basal slip in $\mathrm{Mg}, \mathrm{Mg}$ alloy and $\mathrm{Zn}$ single crystals.

and $\mathrm{Mg}$ alloy single crystals and (0001) indentations are formed due to activations of both basal and SPCS in Zn.

\subsection{Relationships between indentation size and activa- tion of twins and basal slips when indented on (1010) and $(\mathbf{1 2} 10)$}

(1010) and (12 10$)$ indentations elongated to [0001] with twins and slip lines observed around the indentations. Figures 10 and 11 show (a) indentation size on (1010) and (1210); (b) $\{10 \overline{1} 2\}$ twin area; and (c) CRSS for basal slip in $\mathrm{Mg}, \mathrm{Mg}$ alloy and $\mathrm{Zn}$ single crystals. First, comparison of $\mathrm{Mg}$ with $\mathrm{Zn}$ reveal indentation sizes of $\mathrm{Zn}$ smaller than those of $\mathrm{Mg}$ on both (1010) and (12)10) planes. Also, twins were not observed in $\mathrm{Zn}$. Thus, the magnitude relation of indentation size and twin area showed the same tendency. Furthermore, CRSSs for basal slip in $\mathrm{Mg}$ and $\mathrm{Zn}$ are approximately identical, indicating that differences between indentation sizes in $\mathrm{Mg}$ and $\mathrm{Zn}$ would be caused by activation of $\{10 \overline{1} 2\}$ twins. Second, $09 \mathrm{Y}$ and $\mathrm{Zn}$ indentations with no $\{10 \overline{1} 2\}$ twins were compared. 09Y indentation sizes were smaller than those of $\mathrm{Zn}$ on both indentation planes. On the other hand, CRSS for basal slip in Zn is $1 / 10$ or less than that in 09Y. Therefore, the difference between the indentation sizes in $09 \mathrm{Y}$ and $\mathrm{Zn}$ can be explained by the activation of basal slip. Thus, indentation sizes on (1010) and (12 10$)$ in magnesium single crystals are determined by the activation of both basal slip and $\{10 \overline{1} 2\}$ twin. In addition, indentation sizes decreased by increasing CRSSs for both basal slip and $\{10 \overline{1} 2\}$ twin due to the addition of alloying elements. 


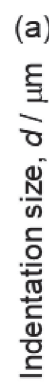
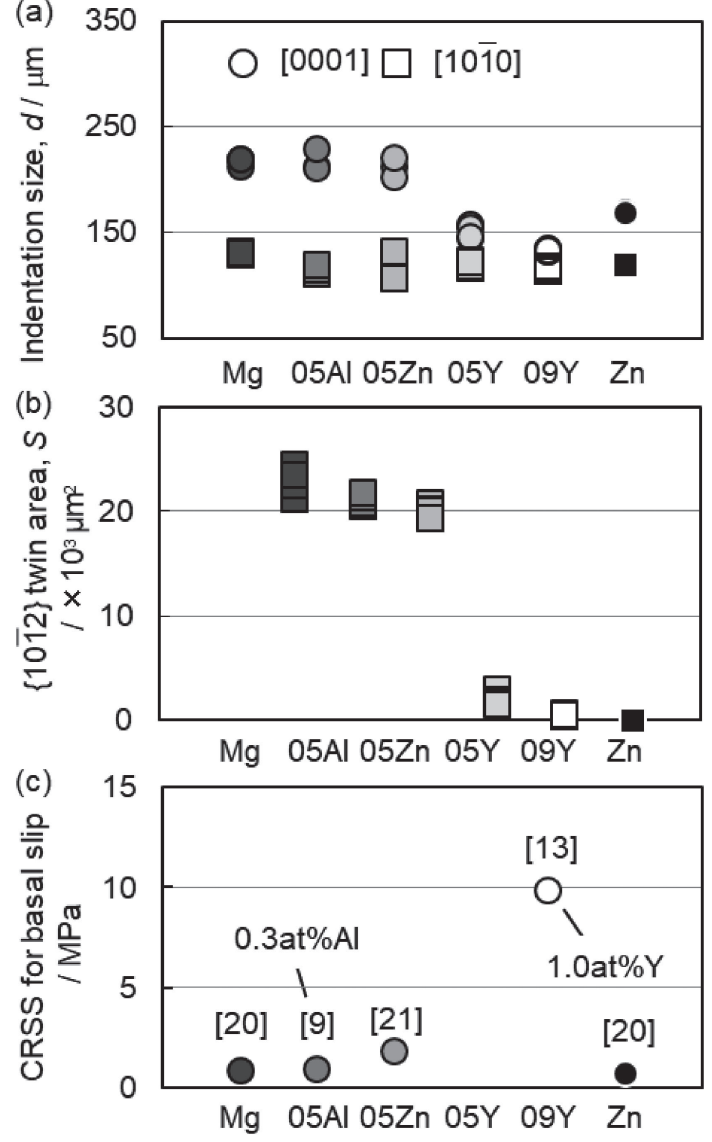

Fig. 11 (a) Indentation size on (12̄10), (b) $\{10 \overline{1} 2\}$ twin area and (c) CRSS for basal slip in $\mathrm{Mg}, \mathrm{Mg}$ alloy and $\mathrm{Zn}$ single crystals.

Comparison of $\mathrm{Mg}, 05 \mathrm{Al}$ and $05 \mathrm{Zn}$ revealed that diameters in [0001] direction on (1010) decreased by the addition of $\mathrm{Al}$ and $\mathrm{Zn}$, but barely changed on $(1 \overline{2} 10)$. Causes for this will be investigated in future studies.

Twin area in 09Y was smaller than that in 05Y, suggesting that CRSS for $\{10 \overline{1} 2\}$ twin increased with increasing yttrium content. Mineta et al. ${ }^{26)}$ reported that CRSS for $\{10 \overline{1} 2\}$ twin was estimated to be $31.0 \mathrm{MPa}$ in $\mathrm{Mg}-0.8$ at\% $\mathrm{Y}$ single crystals using compression tests and was higher than that in pure magnesium of $2.5 \mathrm{MPa}^{27)}$ As shown in Figs. 2 and 3, indentation morphology changed from elliptic to circular with increasing yttrium content, revealing the change in slip degree. Rikihisa et al. ${ }^{14)}$ applied $\mathrm{Mg}-\mathrm{Y}$ alloy single crystals with different yttrium contents to tensile tests and reported that not only SPCS but also first order pyramidal $\langle c+a\rangle$ slip (FPCS) were activated and that CRSS for FPCS increased by yttrium addition. Therefore, the difference between morphologies in $05 \mathrm{Y}$ and $09 \mathrm{Y}$ indentations would be caused by the difference in the activation of FPCS. The present study shows that $(10 \overline{1} 0)$ and $(1 \overline{2} 10)$ indentation sizes strongly depend on CRSSs for basal slip, the main slip, and for $\{10 \overline{1} 2\}$ twin, though the activities of non-basal slip depends on $\mathrm{Mg}$ alloy type.

\section{Conclusion}

Indentation tests of pure magnesium, $\mathrm{Mg}-0.5$ at\% $\mathrm{Al}$ alloy, $\mathrm{Mg}-0.5$ at $\% \mathrm{Zn}$ alloy, $\mathrm{Mg}-0.5$ at\% Y alloy, $\mathrm{Mg}-0.9$ at\% Y alloy and pure zinc single crystals were carried out using a spherical indenter to investigate deformation behavior beneath indentations. The main results are as follows:

All (0001) indentations showed circular morphology. Also, neither slip lines nor twins were observed around the indentations. (0001) indentation sizes in $\mathrm{Mg}$ and $\mathrm{Mg}$ alloy single crystals greatly depend on critical resolved shear stress (CRSS) for basal slip, while (0001) indentation sizes in pure zinc single crystals depend on CRSSs for both basal slip and SPCS. Both (10 $\overline{1} 0)$ and (1 $\overline{2} 10)$ indentations showed elliptical morphology elongated to [0001]. Basal slips and $\{1012\}$ twins were observed around indentations in $\mathrm{Mg}-\mathrm{Al}$ and $\mathrm{Mg}-\mathrm{Zn}$ alloy single crystals. Yttrium addition increased CRSS for $\{10 \overline{1} 2\}$ twin, resulting in an almost complete absence of observable twin. In addition, further increasing yttrium content altered FPCS activities; indentation morphology also became more circular. On the other hand, in pure zinc, no $\{10 \overline{1} 2\}$ twins were observed around indentation; also, a large and small amount of etch pits caused by basal slips and SPCS were respectively observed. Both (1010) and (1210) indentation sizes greatly depend on CRSS for basal slip and $\{10 \overline{1} 2\}$ twin.

\section{Acknowledgment}

A portion of the present study was financially supported by MEXT KAKENHI Grant Number 15K06425 and The Light Metal Educational Foundation, Inc. The authors are very grateful for the support.

\section{REFERENCES}

1) H. Yoshinaga and R. Horiuchi: Trans. JIM 5 (1964) 14-21.

2) H. Tonda, S. Fujiwara and T. Kawasaki: J. Japan Inst. Metals 47 (1983) 927-932.

3) T. Kitahara, S. Ando, M. Tsushida, H. Kitahara and H. Tonda: Key Eng. Mater. 345-346 (2007) 129-132.

4) K. Fukuda, Y. Koyanagi, M. Tsushida, H. Kitahara, T. Mayama and S. Ando: Mater. Trans. 58 (2017) 587-591.

5) N. Iida, S. Ando, M. Tsushida, H. Kitahara and H. Tonda: Key Eng. Mater. 345-346 (2007) 307-310.

6) Y. Kido, A. Nakamura, S. Tsunoda, M. Tsushida, H. Kitahara and S. Ando: Mater. Trans. 59 (2018) 1739-1746.

7) H. Kitahara, T. Mayama, K. Okumura, Y. Tadano, M. Tsushida and S. Ando: Acta Mater. 78 (2014) 290-300.

8) G. Nayyeri, W.J. Poole, C.W. Sinclair, S. Zaefferer, P.J. Konijnenberg and C. Zambaldi: Mater. Sci. Eng. A 670 (2016) 132-145.

9) E.D. Levine, W.F. Sheely and R.R. Nash: Trans. Metall. AIME 215 (1959) 521-526.

10) A. Akhtar and E. Teghtsoonian: Philos. Mag. 25 (1972) 897-916.

11) S. Ando, M. Tsushida and H. Kitahara: Mater. Sci. Forum 706-709 (2012) 1122-1127.

12) A. Akhtar and E. Teghtsoonian: Acta Metall. 17 (1969) 1339-1349.

13) S. Miura, S. Imagawa, T. Toyoda, K. Ohkubo and T. Mohri: Mater. Trans. 49 (2008) 952-956.

14) H. Rikihisa, T. Mori, M. Tsushida, H. Kitahara and S. Ando: Mater. Trans. 58 (2017) 1656-1663.

15) R.W. Hertzberg, R.P. Vinci and J.L. Hertzberg: Deformation and Fracture Mechanics of Engineering Materials, (John Wiley \& Sons, Inc., Hoboken, 2012) pp. 117-120.

16) H. Yoshinaga: Chumitsu Ropposho Kinzoku no Henkei Soushou, (Uchida Rokakuho Publishing Co., Ltd., Tokyo, 2007) pp. 68-72.

17) Japanese Standards Association: JIS Handbook Non-Ferrous Metals \& Metallurgy: English Version 2016, (Japanese Standards Association, Tokyo, 2016) pp. 113-135. 
18) H. Tonda, T. Gotoh, Y. Nakashima and T. Kawasaki: J. Japan Inst. Metals 39 (1975) 351-357.

19) T. Mineta, S. Miura, K. Oka and T. Miyajima: Mater. Trans. 59 (2018) 602-611.

20) S. Kohda: Introduction to Metal Physics, (CORONA PUBLISHING CO., LTD., Tokyo, 1973) p. 156.

21) S. Miura, S. Yamamoto, K. Ohkubo and T. Mohri: Mater. Sci. Forum 350-351 (2000) 183-190.

22) S. Ando, M. Tsushida and H. Kitahara: Mater. Sci. Forum 654-656 (2010) 699-702.
23) S. Ando, M. Tsushida and H. Kitahara: The 8th Pacific Rim International Congress on Advanced Materials and Processing, ed. by Fernand Marquis, (TMS, 2013) pp. 979-985.

24) H. Tonda and T. Kawasaki: J. Japan Inst. Metals 47 (1983) 373-374.

25) H. Kitahara, M. Tsushida and S. Ando: Mater. Trans. 57 (2016) 1246 1251 .

26) T. Mineta, S. Miura, T. Mukai, M. Ueda and T. Mohri: J. Japan Inst. Met. Mater. 77 (2013) 466-472.

27) R.L. Bell and R.W. Cahn: Proc. R. Soc. London Ser. A 239 (1957) 494-521. 